\title{
Reproductive Characteristics of Feral Raccoons (Procyon lotor) Captured by the Pest Control in Kamakura, Japan
}

\author{
Takuya $\mathrm{KATO}^{1) *}$, Yayoi ICHIDA $^{1)}$, Kazumi TEI ${ }^{1)}$, Makoto ASANO $^{2)}$ and Shin-ichi HAYAMA ${ }^{1)}$ \\ ${ }^{1)}$ Laboratory of Wildlife Medichine, Nippon Veterinary and Life Science University, 1-7-1 Kyonan-cho, Musashino-shi, Tokyo 180-8602 and \\ ${ }^{2)}$ Laboratory of Zoo and Wildlife Medicine, Faculty of Applied Biological Sciences, Gifu University, 1-1 Yanagido, Gifu 501-1193, Japan
}

(Received 6 February 2009/Accepted 8 July 2009)

ABSTRACT. In order to examine reproductive characteristics of feral raccoons in Kamakura, 335 raccoons were collected from March 2005 to March 2007. Raccoons were classified into five age classes: Class I, less than 5 months old; Class II, 5-11 months; Class III, 12-17 months; Class IV, 18-23 months; and Class V, over 23 months old. Females were examined for their age specific pregnancy rate and litter size. To determine when raccoon births occur in the region, birth months of fetuses were estimated by the fetal growth rate, and birth months of Class I individuals were examined by tooth eruption. From fetuses of 18 pregnant females and 47 Class I individuals, it was found that the raccoon births occur from February to October. Of 163 females examined, all of Class I-II females were nulliparous. Pregnancy rate was $47.6 \%$ in Class III females, which was significantly lower than $75.0 \%$ in Class IV and $78.1 \%$ in Class V. The litter size of fetuses ranged from 2 to 5 , and 3.9 on average; and that of placental scars ranged from 1 to $7,3.8$ on average. Our findings suggest that parturition of raccoons is a bimodal distribution and age at first parturition may occur between 12 and 17 months old. In order to reduce the raccoon population successfully, females of all ages should be captured throughout the year.

KEY WORDS: litter size, parturition, pregnancy rate, Procyon lotor, raccoon.

J. Vet. Med. Sci. 71(11): 1473-1478, 2009

Reproductive characteristics have an influence on the population dynamics in wild mammals. Breeding season, pregnancy rate, and litter size are often useful data for wildlife management. Reproductive characteristics should also be investigated for monitoring of the alien species control program.

The raccoon (Procyon lotor) is native to North America, and considered as invasive alien species in Japan. The first report of raccoon naturalization was made in 1962 and the animals are known to have escaped from a zoo in Inuyama, Aichi [1]. The feral raccoon has been distributed to all prefectures of Japan because of naturalization by escapes from captivity and intentional releases [9-11, 17]. In Kamakura, raccoon naturalization was identified in 1988 [23], and the feral raccoons have been captured to control the damage of invading houses [11]. Kanagawa Government formulated raccoon control program in 2006 [15], with the basis of the Invasive Alien Species Act in 2005. Reproduction of raccoons in North America has been studied extensively [18, $20,24,25,27,28]$, and reproductive characteristics have been considered to vary in the different distribution $[5,6$, $24,30]$. In recent years, several studies of feral raccoon reproduction have been published in Japan [2, 16, 29]. Like in North America, not only adults but also yearlings of the feral raccoon were reported to mate in breeding season [2, 29]. In Kanagawa, although many raccoons have been captured by the pest control actions, female reproductive characteristics are not well known. Kanagawa raccoon control program was formulated on the basis of previous studies to

\footnotetext{
* Correspondence to: Kato, T., Laboratory of Wildlife Medichine, Nippon Veterinary and Life Science University, 1-7-1 Kyonan-cho, Musashino-shi, Tokyo 180-8602, Japan.

e-mail: takuya-v-magna@mub.biglobe.ne.jp
}

control the population size of feral raccoons. However, to decrease the raccoon population size efficiently, it is necessary to understand the reproductive characteristics of the feral raccoons in Kanagawa.

The purpose of our study was thus to analyze the reproductive characteristics of feral raccoons in Kanagawa. In this paper, we classified the animals into 5 age classes to examine age specific reproductive characteristics in more details. We then examined the birth months, pregnancy rate, and litter size of feral raccoons captured by the annual pest control in Kamakura, Kanagawa.

\section{MATERIALS AND METHODS}

In total, 335 raccoon carcasses were collected by the pest control actions in Kamakura, Kanagawa (N35 ${ }^{\circ}$ E139 ${ }^{\circ}$ ), from March 2005 to March 2007 (Table 1). In this area, the climate is temperate with humid summer and dry winter, and the mean annual temperature is $15.5^{\circ} \mathrm{C}$ and the annual sunshine duration is $1920.6 \mathrm{hr}$. All of the 335 animals were captured using box traps (Havahart Model 1089, Woodstream, Litiz, Pennsylvania, U.S.A., or handmade by trappers) around the houses invaded by the raccoons. These raccoons were euthanized by trappers using $\mathrm{CO}_{2}$, according to the Guidelines for the management of invasive alien species [12]. From each carcass, sex of the raccoon was distinguished by identifying the reproductive organs, tooth eruption was observed, and then the skinned head and reproductive organs were removed. For later examinations, skinned heads were frozen at $-25^{\circ} \mathrm{C}$ and reproductive organs were fixed in $10 \%$ formalin neutral buffer solution. After skinned heads were processed into skulls, root foramina closure of canines and cranial suture obliteration were 
recorded from them.

The raccoons were then separated into 5 age classes by the following methods of age determination:

Class I. Less than 5 months old: All permanent teeth not erupted [22].

Class II. 5 to 11 months old: All permanent teeth erupted and root foramina of canines open [8].

Class III. 12 and 17 months old: Root foramina of canines closed and interfrontal suture not obliterated [13] (Fig.1-a).

Class IV. 18 and 23 months old: Interfrontal suture obliterated (Fig.1-b) and interpalatine suture not obliterated [13] (Fig.1-c).

Class V. Over 23 months old: Interpalatine suture obliterated [13] (Fig.1-d).

Sex ratio and age classes were determined for all raccoons except for 4 males and a female which were not available for age class determination due to broken skull samples.

For estimating litter size, the number of fetuses was counted from pregnant females. Non-pregnant females often had the placental scars in uteri, and the number of placental scars was also counted to estimate litter size [2]. If 2 distinct sets of scars were observed in the same uterus, only
Table 1. Monthly number of captured raccoons by pest control in Kamakura, 20052007

\begin{tabular}{ccc}
\hline \multirow{2}{*}{ Month } & \multicolumn{2}{c}{ Numbers of raccoons } \\
\cline { 2 - 3 } & female & male \\
\hline Jan & 6 & 12 \\
Feb & 12 & 11 \\
Mar & 14 & 20 \\
Apr & 10 & 17 \\
May & 13 & 13 \\
Jun & 13 & 18 \\
Jul & 16 & 11 \\
Aug & 14 & 15 \\
Sep & 18 & 12 \\
Oct & 19 & 15 \\
Nov & 19 & 14 \\
Dec & 10 & 13 \\
\hline total & 164 & 171 \\
\hline
\end{tabular}

the darker scars were counted for litter size analysis. We considered pregnant females and females having scars in uteri as parous females. Pregnancy rates were calculated from the proportion of parous females. In pregnant females, the crown-rump lengths (CRL) of the fetuses were measured

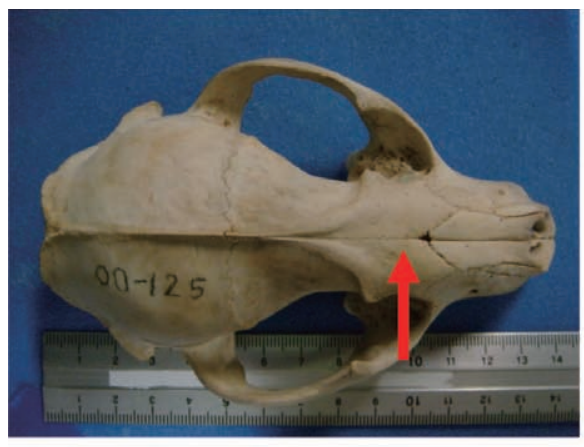

a

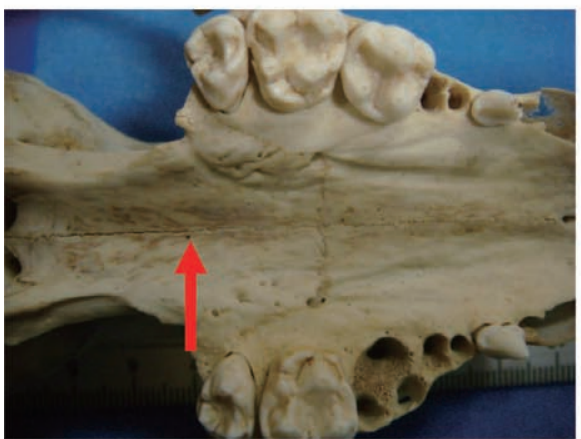

c

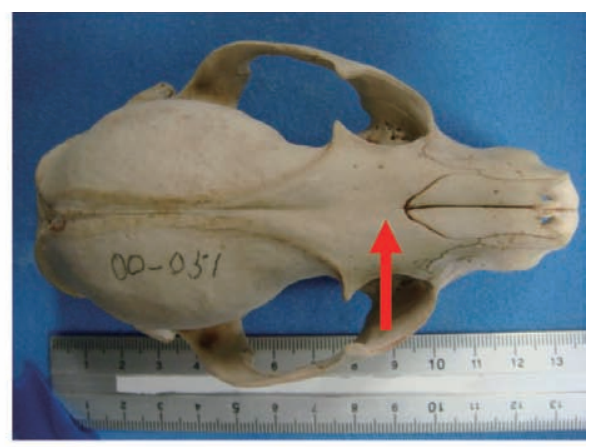

b

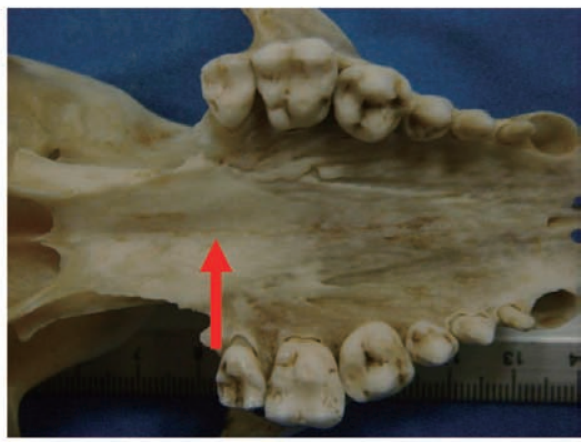

$\mathrm{d}$

Fig. 1. The cranial suture obliteration of raccoons (described in Junge and Hoffmeister, 1980). a. The interfrontal suture has not been obliterated at the area pointed by the arrow, which indicates that the sample is less than 18 months old. b. The interfrontal suture has been obliterated at the area pointed by the arrow, which indicates that the sample is over 18 months old. c. The interpalatine suture has not been obliterated at the area pointed by the arrow, which indicates that the sample is less than 24 months old. d. The interpalatine suture has been obliterated at the area pointed by the arrow, which indicates that the sample is over 24 months old. 
to the nearest $\mathrm{mm}$, and average CRL was calculated per litter. For each fetus, the potential date of birth was obtained using the growth rate of raccoon fetuses [19].

Birth months of Class I raccoons were determined by their tooth eruption [22]. In order to control for an effect of litter size variances, animals were considered as a litter only if it was shown that they were captured at the same point and time by trapper's information.

From the birth months estimated by the fetal growth rate and the tooth eruption examination in Class I individuals, it was determined when raccoons were born in the region.

Statistical analyses were carried out using chi-square test or Fisher's exact test for evaluating pregnancy rates among the age classes, and Kruskal-Wallis test between mean litter sizes. We considered $\mathrm{p}$ value $<0.05$ to be statistically significant. These analyses were carried out on a computer using SPSS10.0J for Windows.

\section{RESULTS}

Throughout the study period, 167 males and 163 females were determined for sex and classified into the five age classes (Table 2).

Pregnant females were collected in February $(n=1)$, March ( $n=11)$, April $(n=4)$, June $(n=2)$, and July $(n=1)$. One of the litters of 19 females was so small that measurement of the fetal CRL was not possible. From the growth rate of raccoon fetuses, the potential birth months of 18 litters were estimated to range from March to June, and August. The mid point of the estimated birth dates was May 5. In addition, birth months of 47 Class I raccoons were estimated to range from February to October. By combining these data associated with parturition, it was found that these raccoons in Kamakura were born from February to October (Fig. 2). Parturition gradually increased until May, dropped in June and another smaller peak was found between July and September.
Table 2. Age specific sex ratio with divided five age classes of raccoons collected in Kamakura, 2005-2007

\begin{tabular}{ccc}
\hline \multirow{2}{*}{ Age class } & \multicolumn{2}{c}{ Numbers of raccoons } \\
\cline { 2 - 3 } & female & male \\
\hline Class I & 30 & 26 \\
Class II & 35 & 75 \\
Class III & 21 & 24 \\
Class IV & 36 & 23 \\
Class V & 41 & 19 \\
\hline total & 163 & 167 \\
\hline
\end{tabular}

Table 3. Age specific pregnancy rate of feral raccoons captured in Kamakura, 2005-2007

\begin{tabular}{ccccc}
\hline & & \multicolumn{3}{c}{ Parous females } \\
\cline { 3 - 5 } Age class & $\mathrm{N}$ & Pregnancy & Presence of scars & $\%^{\mathrm{a})}$ \\
\hline Class I & 30 & 0 & 0 & 0 \\
Class II & 35 & 0 & 0 & 0 \\
Class III & 21 & 4 & 6 & 47.6 \\
Class IV & 36 & 8 & 19 & 75.0 \\
Class V & 41 & 7 & 25 & 78.1 \\
\hline total & 164 & 19 & 50 &
\end{tabular}

a) Pregnancy rate was calculated from pregnant females and females having placental scars in uteri.

Pregnancy rates of Class I-Class V raccoons captured in Kamakura in 2005-2007 are shown in Table 3. The parous females were found in Class IV $(75.0 \%)$ and Class V (78.1\%), while all of Class I ( $0 \%)$ and Class II $(0 \%)$ females were nulliparous. Of Class III raccoons, 4 females were pregnant and 6 had scars in uteri. The proportion of parous females in Class III was $47.6 \%$ in 2005-2007. There was no significant difference in the proportion of parous females between Class IV and Class V, but the proportion in Class III was lower than that in Class IV $(p=0.048)$ and Class V $(p=0.022)$. When Class III and Class IV were combined as

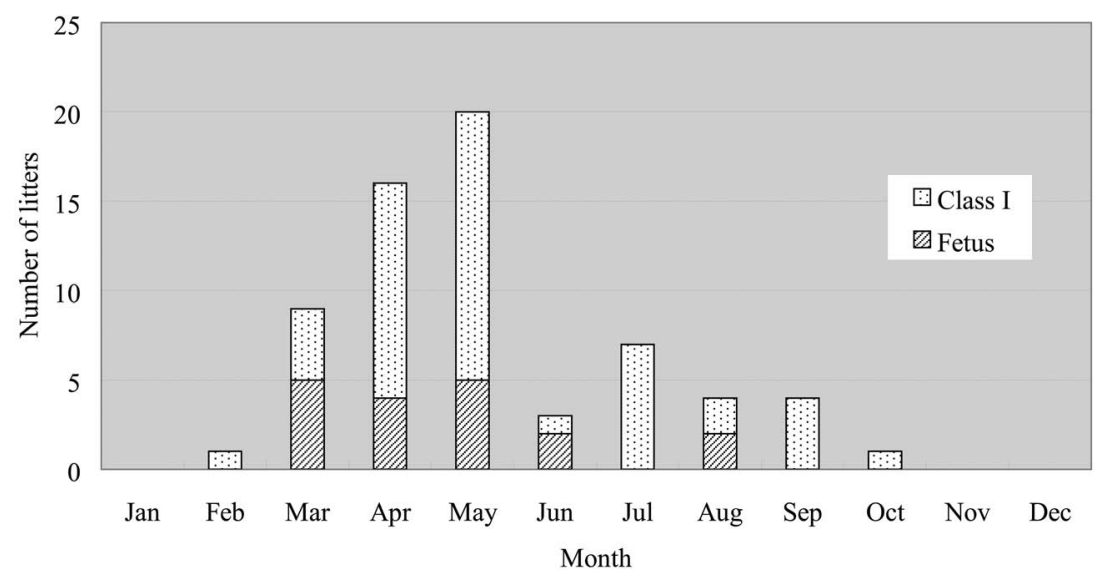

Fig. 2. Parturition periods in raccoons estimated from birth month of Class I and fetuses growth rates in Kamakura, 2005-2007. The potential birth months were estimated from fetus growth rate [Llewellyn, 1953] and the birth months were estimated from tooth eruption of Class I [Montgomery, 1964]. 
Table 4. Age specific mean litter sizes of feral raccoons captured in Kamakura, 2005-2007

\begin{tabular}{ccccc}
\hline Age class & $\mathrm{N}$ & Mean number of fetuses $( \pm \mathrm{SD})$ & $\mathrm{N}$ & Mean number of scars $( \pm \mathrm{SD})$ \\
\hline Class III & 4 & $3.3 \pm 1.3$ & 6 & $3.3 \pm 0.5$ \\
Class IV & 8 & $4.1 \pm 0.8$ & 19 & $3.6 \pm 1.0$ \\
Class V & 7 & $4.1 \pm 1.2$ & 25 & $4.0 \pm 1.6$ \\
\hline total & 19 & 50 & \\
\hline
\end{tabular}

yearlings, the pregnancy rate of the yearlings was $64.9 \%$, which did not differ from that of Class $\mathrm{V}$, which was considered as adults $(\mathrm{p}=0.18)$.

In order to examine the annual litter size in Kamakura during 2005-2007, the number of fetuses and placental scars were counted. The number of fetuses in 19 pregnant females ranged from 2 to 5 , and averaged to $3.9(n=19$, $\mathrm{SD}=1.1$ ), while the number of placental scars in 50 females ranged from 1 to 7 , and averaged to $3.8(\mathrm{n}=50, \mathrm{SD}=1.3)$. The number of placental scars were not different from that of fetuses $(p>0.1)$. Age class specific litter sizes were calculated using the counts of fetuses and placental scars in 20052007 (Table 4). Throughout Class III-Class V, the number of fetuses ranged from 2 to 5 . The numbers of placental scars in Class III, Class IV, and Class V were in the range of $3-4,2-5$, and $1-7$, respectively. However, neither the number of fetuses nor that of placental scars was found to differ significantly among the age classes.

\section{DISCUSSION}

Parturition periods: In North America, Gehrt [6] discussed that parturition of raccoons typnically occurs in April at northern latitudes such as Illinois $\left(\mathrm{N} 40^{\circ}\right)$ [27], and sometime later at southern latitudes: West Virginia (N38 ${ }^{\circ}$ ), until August [3]; southwestern Georgia and northwestern Florida $\left(\mathrm{N} 31^{\circ}\right)$, until early October[21]; and southern Texas $\left(\mathrm{N} 28^{\circ}\right)$, until September [7].

Litters of the feral raccoons in Hokkaido $\left(\mathrm{N} 43^{\circ}\right)$ were estimated to be born between March and May, but some females were also found pregnant in July [2]. On the other hand, parturition period of raccoons in Wakayama $\left(\mathrm{N} 33^{\circ}\right)$, was typically estimated to range from April to August, and it was suggested that late litters were also born in autumn [29]. In our study, raccoons were estimated to be born from February to October in Kamakura $\left(\mathrm{N} 35^{\circ}\right)$. This finding demonstrates that parturition periods of raccoons in Japan also become later and more extensive among the southern latitudes, like in North America.

Kaneko et al. [16] reported that male raccoons of Kanagawa decrease testicular function even in summer. Although this phenomenon occurs in some adult males, other adult males may maintain testicular function. Our results suggest that raccoons are born until October in Kamakura, which indicate that some males in the region retain testicular function and mate during summer.

In our study, parturition periods of raccoons in Kamakura were suggested to be in a bimodal distribution (Fig. 2). Late litters in summer are reported at several locations in North America, at more northern latitudes than Kamakura [2, 3, 6], however, only the study at southern Texas confirmed a bimodal distribution in the parturition periods of raccoons [7]. The climate of Kamakura is different from the subtropical climate of southern Texas, and in this study, it was not possible to examine how various factors influence the distribution of raccoon parturition periods. However, the bimodal distribution was suggested for the first time in Japan, at the latitude more northern than southern Texas.

Pregnancy rate: When Class III and Class IV females were combined as yearlings, pregnancy rate of yearlings was $64.9 \%$ and it did not differ from that of Class V females, which were considered as adults $(p=0.18)$. It was reported that the pregnancy rate of yearlings varied among locations: Michigan $\left(\mathrm{N} 42^{\circ}\right), 54 \%$ [28]; Iowa $\left(\mathrm{N} 40^{\circ}\right), 59 \%$ [4]; Illinois, 73\% [14]; Missouri (N39 $)$, 38-77\% [5]; and Hokkaido, $66 \%$ [2]. The pregnancy rate of yearlings in our study was $64.9 \%$, and was not different from that of Hokkaido. Gehrt [6] did not report that the pregnancy rate of yearlings varied among latitudes of the population. In this study, it was also not possible to examine whether the pregnancy rate of yearlings varied among latitudes in Japan.

Juvenile females may reach sexual maturity by their first mating season and produce litters in North America [6]. In our study, although all of Class II females were nulliparous, approximately $50 \%$ of Class III females were mating in their first year. In addition, the pregnancy rate of Class III females was lower than that of Class IV and Class V. Therefore, it is considered that the first parturition age of the raccoons in Kamakura is between 12 and 17 months old.

Litter size: The placental scars have been used to estimate litter sizes in previous studies because some reports suggested that the number of placental scars is close to litter size in raccoons $[2,4,5,14,24,28]$. In North America, mean litter size of raccoon was reported to range from 2.0 to 4.8 depending on the location $[24,30]$. Mean litter size of adults was larger than that of yearlings in Iowa [4], Missouri [5], and Illinois $[5,14]$. Because of the small sample size in our study, no significant differences in mean litter sizes were observed among the age classes. Mean litter size calculated from fetal numbers was $3.2(n=5, S D=1.8)$, and mean litter size estimated from placental scars was 3.9 $(n=98, S D=1.3)$ in adults, while $3.6(n=47, S D=1.3)$ in yearlings in Hokkaido [2]. In Tanabe, Wakayama, the average litter size calculated from fetal numbers was $3.2(n=26)$ [29]. Ritke [24] reported that there was a significant positive correlation between litter size and latitude in North 
America. Using the count data of placental scars, no significant difference in mean litter sizes was also found when the comparison was made between the 2 Japanese populations at distinctive latitudes, Kamakura and Hokkaido(mean litter size $=3.8$ ) [2]. The origins of the introduced raccoons in Japan have not been identified [9], however, it is assumed that they have been brought in from various populations in North America. Therefore, if no correlation between litter size and latitude is found among the feral raccoons in Japan, we assume that the litter size should be determined by genetic factors, and not by latitude.

Placental scars could not be seen in pregnant females and females at/or near estrus [26]. In Hokkaido, where most females were collected in July and August, the peak of mating was reported to be in February [2]. On the other hand, females in Kamakura were collected throughout the year and the mating season was considered to last for a long time. In addition, when estrus of the raccoons occurs in Kamakura is not well known and little was known about the degenerative process of placental scars. Therefore, the number of placental scars may have been underestimated in some females. The degenerative process of placental scars in uterus must be revealed in order to estimate the pregnancy rate and litter size of raccoons more accurately.

Management implications: Our results demonstrate that the raccoons in Kamakura have the high reproductive potential, which may be comparable to the populations in North America. Reproductive characteristics of raccoons are likely to vary among locations in Japan. Our result suggests that the parturition periods of raccoons in Japan are related to the latitudes. Additionally, the first parturition of the female raccoons in Kamakura occurs between 12 and 17 months old. It is recommended that female raccoons in Kamakura, at all ages, should be captured as many as possible throughout the year, because the parturition periods of these raccoons are from February to October and the females as young as 12 months old can start reproducing.

Based on the Invasive Alien Species Act, numbers of raccoons have been captured to reduce the raccoon population in Kanagawa, however, the problem here is that, in most cases, only the individuals which have caused the damage to crops and/or invaded houses are being captured [11]. For controlling raccoon damage and leading to eradication from Japan, captured raccoons should be investigated as much as possible to obtain monitoring parameters such as reproductive characteristics and other valuable data. For example, information such as whether the animal is a parous female, litter size, size of fetuses should be obtained. Managers should use these data to make a more effective trapping plan.

Finally, our study did not demonstrate the nutrition of raccoons in Kamakura because there were no comparable studies to consider the association between reproduction and nutrition. It is necessary to establish the methods to obtain a comparative nutritional index to estimate the nutritional level of the feral raccoons.
ACKNOWLEDGMENTS. We wish to thank Prof. T. Tsutsui for his helpful suggestions; Kamakura local government office for its cooperation in building raccoons retrieving system; Mr. S. Kato, president of Strain Ltd., for helping us retrieving raccoons and providing important information about the captured raccoons; Mr. M. Kaneda, Dr. K. Suzuki, Mr. Y. Kaneshiro and Prof. T. Ikeda for research assistance and providing information. We are also grateful to the cacodaemon network and members of Laboratory of Wildlife Medicine, Nippon Veterinary and Life Science University for their assistance with analyses. Finally, we also thank Ms. S. Arai for her critical comments on the manuscript.

\section{REFERENCES}

1. Ando, S. and Kajiura, K. 1985. Status of raccoons in Gifu Prefecture. Bull. Gifu Pref. Museum 6: 23-30 (in Japanese).

2. Asano, M., Matoba, Y., Ikeda, T., Suzuki, M., Asakawa, M. and Ohtaishi, N. 2003. Reproductive characteristics of the feral raccoon (Procyon lotor) in Hokkaido. J. Vet. Med. Sci. 65: 369-373.

3. Berard, E. V. 1952. Evidence of a late birth for the raccoon. $J$. Mammal. 33: 247-248.

4. Clark, W. R., Hasbrouck, J. J., Kienzler, J. M. and Glueck, T. F. 1989. Vital statistics and harvest of an Iowa raccoon population. J. Wildl. Manage. 53: 982-990.

5. Fritzell, E. K., Hubert, G. F. Jr., Meyen, B. E. and Sanderson, G. C. 1985. Age-specific reproduction in Illinois and Missouri raccoons. J. Wildl. Manage. 7: 60-73.

6. Gehrt, S. D. 2003. Raccoons Procyon lotor and allies. pp. 611634. In: Wild Mammals of North America: Biology, Management and Conservation. 2nd ed. (Feldhamer, G. A., Thompson, B. C. and Chapman, J. A. eds.), Johns Hopkins University Press, Baltimore.

7. Gehrt, S. D. and Fritzell, E. K. 1996. Second estrus and late litters in raccoons. J. Mammal. 77: 388-393.

8. Grau, C. A., Sanderson, G. C. and Rogers, J. P. 1970. Age determination of raccoons. J. Wildl. Manage. 34: 364-372.

9. Ikeda, T. 1999. Progress of naturalization of raccoons and related problems in Hokkaido. The Annual Report on Cultural Science, Faculty of letters. Hokkaido Univ. 47:149-175 (in Japanese).

10. Ikeda, T. 2006. Problem controlling the invasive raccoon in Japan. Honyurui Kagaku (Mamm. Sci.) 46: 95-97 (in Japanese).

11. Ikeda, T., Asano, M., Matoba, Y. and Abe, G. 2004. Present status of invasive alien raccoon and its impact in Japan. Global Environ. Res. 8: 125-131.

12. Japan Veterinary Medical Association. 2007. Guidelines for the management of invasive alien species. The Wildlife Committee Report. Division of small animal medicine in JVMA (in Japnaese).

13. Junge, R. E. and Hoffmeister, D. F. 1980. Age determination in raccoons from cranial suture obliteration. J. Wildl. Manage. 44: 725-729.

14. Junge, R. E. and Sanderson, G. C. 1982. Age related reproductive success of female raccoons. J. Wildl. Manage. 46: 527529.

15. Kanagawa Government. 2006. Kanagawa Raccoon Control Program (in Japanese). 
16. Kaneko, K., Akiya, Y., Sato, H., Tanaka, A., Aoki, H., Miyoshi, M., Abukuma, T., Mochizuki, M. and Kawakami, S. 2005. Seasonal influence on testicular function of male raccoons. Procyon lotor. J. Reprod. Dev. 51: 477-482.

17. Kaneshiro, Y. and Yachimori, S. 2007. The raccoon Procyon lotor captured in Ehime Prefecture Matsuyama City. Bull. Shikoku Inst. Natural History 4: 27-29 (in Japanese).

18. Kaufman, J. H. 1982. Raccoon and allies. pp. 567-585. In: Wild mammals of North America: Biology, Management and Economics (Chapman, J. A. and Feldhammer, G. A. eds.), The Johns Hopkins University Press, Baltimore.

19. Llewellyn, L. M. 1953. Growth rate of the raccoon fetus. $J$. Wildl. Manage. 17: 320-321.

20. Lotze, J.H. and Anderson, S. 1979. Procyon lotor. Mamm. Species 119: 1-8.

21. Mckeever, S. 1958. Reproduction in the raccoon in the southern United States. J. Wildl. Manage. 22: 211.

22. Montgomery, G. C. 1964 . Tooth eruption in preweaned raccoons. J. Wildl. Manage. 28: 582-584.

23. Nakamura, K. 1991. A note on the naturalization of common raccoon in Kanagawa Prefecture. Natural History Rep. Kanagawa 12: 17-19 (in Japanese).
24. Ritke, M. E. 1990. Quantitative assessment of variation in litter size of the raccoon Procyon lotor. Am. Midl. Nat. 123: 390 398.

25. Rosatte, R.C. 2000. Management of raccoons (Procyon lotor) in Ontario, Canada: Do human intervention and disease have significant impact on raccoon populations? Mammalia 64: 369-390.

26. Sanderson, G. C. 1950. Methods of measuring productivity in raccoons. J. Wildl. Manage. 14: 389-402.

27. Sanderson, G. C. and Nalbandov, A. V. 1973. The reproductive cycle of the raccoon in Illinois. Ill. Nat. Hist. Surv. Bull. 31: 29-85.

28. Stuewer, F. W. 1943. Reproduction of raccoons in Michigan. $J$. Wildl. Manage. 7: 60-73.

29. Suzuki, K. 2007. Reproductive performance of feral raccoons in Tanabe, Wakayama. pp. 62-67. In: Research Reports on Wildlife Damage in Tanabe. Tanabe Wildlife Damage Control Committee (in Japanese)

30. Zeveloff, S. I. 2002. Reproduction and development. pp. 121134. In: Raccoons: a Natural History (Bolen, E.A. ed.), The Smithsonian Institution, Washington, D.C. 